\title{
Determinants for early introduction of complementary foods in Australian infants: findings from the HSHK birth cohort study
}

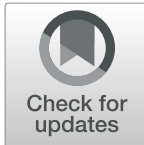

\author{
Amit Arora ${ }^{1,2,3,4^{*}}$, Narendar Manohar ${ }^{1}$, Debra Hector ${ }^{5}$, Sameer Bhole ${ }^{4,6,7,8}$, Andrew Hayen ${ }^{9}$, \\ John Eastwood ${ }^{10,11,12}$ and Jane Anne Scott ${ }^{13}$
}

\begin{abstract}
Objective: The purpose of this study was to examine the timing of introduction of complementary (solid) foods among infants in South Western Sydney, Australia, and describe the maternal and infant characteristics associated with very early introduction of solids.
\end{abstract}

Methods: Mother-infant dyads ( $n=1035$ ) were recruited into the "Healthy Smiles Healthy Kids" study by Child and Family Health Nurses at the first post-natal home visit. Data collected via telephone interviews at 8, 17, 34 and 52 weeks postpartum included timing of introduction of solids and a variety of maternal and infant characteristics ( $n=934$ ). Multiple logistic regression was used to identify factors independently associated with the risk of introducing solids very early, which for the purpose of this study was defined as being before 17 weeks.

Results: The median age of introduction of solids was 22 weeks. In total, 13.6\% ( $n=127)$ of infants had received solids before 17 weeks and $76.9 \%(n=719)$ before 26 weeks of age. The practice of introducing solids early decreased with older age of the mother. Compared to women $<25$ years of age, those who were 35 years or older were $72 \%$ less likely to introduce solids very early $\left(\mathrm{OR}=0.28, \mathrm{Cl}_{95}\right.$ 0.14-0.58). Single mothers had more than twice the odds of introducing solids before the age of 17 weeks compared to married women ( $O R=2.35, \mathrm{Cl}_{95}$ 1.33-4.16). Women who had returned to work between 6 to 12 months postpartum were $46 \%$ less likely to introduce solids very early compared with those who were not working at the child's first birthday ( $\mathrm{OR}=0.54, \mathrm{Cl}_{95} 0.30-0.97$ ). Women born in Vietnam and Indian sub-continent had lower odds of introducing solids very early compared to Australian born women $\left(\mathrm{OR}=0.42, \mathrm{Cl}_{95} 0.21-0.84\right.$ and $\mathrm{OR}=0.30, \mathrm{Cl}_{95} 0.12-0.79$, respectively). Infants who were exclusively formula-fed at 4 weeks postpartum had more than twice the odds of receiving solids very early $\left(\mathrm{OR}=2.34, \mathrm{Cl}_{95}\right.$ 1.49-3.66).

Conclusions: Women who are younger, single mothers, those not working by the time of child's first birthday, those born in Australia, and those who exclusively formula-feed their babies at 4 weeks postpartum should be targeted for health promotion programs that aim to delay the introduction of solids in infants to the recommended time.

Keywords: Complementary feeding, Solids, Infants, Cohort study, Australia

\footnotetext{
* Correspondence: a.arora@westernsydney.edu.au

${ }^{1}$ School of Health Sciences, Western Sydney University Campbelltown

Campus, Locked Bag 1797, Penrith, NSW 2751, Australia

${ }^{2}$ Translational Health Research Institute, Western Sydney University, Locked

Bag 1797, Penrith, NSW 2751, Australia

Full list of author information is available at the end of the article
}

(c) The Author(s). 2020 Open Access This article is distributed under the terms of the Creative Commons Attribution 4.0 International License (http://creativecommons.org/licenses/by/4.0/), which permits unrestricted use, distribution, and reproduction in any medium, provided you give appropriate credit to the original author(s) and the source, provide a link to the Creative Commons license, and indicate if changes were made. The Creative Commons Public Domain Dedication waiver (http://creativecommons.org/publicdomain/zero/1.0/) applies to the data made available in this article, unless otherwise stated. 


\section{Background}

The process of gradual introduction of complementary foods into an infant's diet is essential for meeting the nutritional needs of infants in their first year of life [1]. The decision around when to start introducing complementary foods to their infant is a dilemma faced by every mother. Complementary foods represent all liquid, semisolid, and solid foods other than breast milk, infant formulas and follow-on formulas [2] either commercial or home-made [3]. It is advised that when semi-solid and solid complementary foods (hereafter referred to as solids) are introduced to an infant, their textures should be changed as appropriate to the age of the infant so as to give a variety of textural experiences [4].

From a paediatric health perspective, the timing of introducing solids is a sensitive issue due to the potential effects on children's long-term health status $[5,6]$. Presently, the World Health Organization (WHO) recommends infants should be exclusively breastfed until the age of 6 months, followed by the introduction of nutritious solids to complement on-going breastfeeding [7]. Such a feeding pattern ensures optimal growth and positive health benefits [8]. This guideline has been supported in a slightly modified form by the Australian National Health and Medical Research Council (NHMRC) [9] and the American Academy of Pediatrics [10], with both organisations recommending that solids should be introduced 'around' or 'at about' 6 months of age. However, certain international organisations' guidelines slightly differ. For example, the European Society of Paediatric Gastroenterology Hepatology and Nutrition (ESPGHAN) [11, 12] and European Food Safety Authority [13] recommend that complementary foods be introduced "no earlier than 17 weeks and no later than 26 weeks". Further, the Australian recommendations were recently updated by consensus at an Infant Feeding Summit in May 2016 and it is currently recommended that "When your infant is ready, at around 6 months, but not before 4 months, start to introduce a variety of solids, starting with iron rich foods, while continuing breastfeeding [14].

Undertaking research on complementary feeding practices is essential to identify specific population subgroups of women who decide to introduce solids early and the reasons for not complying with international recommendations. A variety of factors that influence early introduction of solids have been reported in the literature [15], however these factors vary across regions, populations, cultures, and countries [16-18]. In Australia, recent studies report that many parents introduce solids at early ages $[19,20]$. National statistics from the Australian Institute of Health and Welfare show that around $35 \%$ of four-month old's had consumed soft/semi-solid foods [19]. The New South
Wales (NSW) Child Health Survey (2009-2010) reported that $44.6 \%$ of infants were introduced solids before 6 months of age [21].

While national and state-wide statistics are available which indicate the prevalence and predictors of early introduction of solids in infants, there are limited data for families residing in South Western Sydney (SWS) region of NSW. The SWS is a part of Greater Western Sydney region and is considered to be one of the most culturally diverse and socially-disadvantaged populations in Australia [22-24].

The purpose of the current study was three-fold:

a. to examine the timing of introduction of solids to infants residing in South Western Sydney;

b. to ascertain the sociodemographic and biomedical predictors associated with very early introduction of solids in this population group; and

c. to investigate the association of the timing of introduction of solids with the duration of breastfeeding.

These data will indicate the degree of accordance with the existing Australian and International infant feeding recommendations. Additionally, they will assist in identifying women most at risk of introducing solids early and targeting of interventions to improve infant feeding practices with respect to the timing of introduction of solids among particular sub-populations in Australia.

\section{Methods}

\section{Study background}

This study analyses data collected as part of the ongoing Healthy Smiles Healthy Kids (HSHK) cohort study in South Western Sydney that began in late 2009 and which has been described previously [22]. In brief, women who gave birth to a live infant with no serious health condition between October 2009 and February 2010 in public hospitals located under the catchment of the former Sydney South West Area Health Service (now classified as Sydney and South Western Sydney Local Health Districts) were approached to be a part of this study. Child and Family Health Nurses (CFHNs) recruited mother-infant dyads at the first post-natal home visit at four to 6 weeks, as this is the primary point of community-based health professional contact for newborn children and their parents/carers [25]. At the first post-natal visit, CFHNs explained the project to the mothers and obtained written informed consent. If requested, the nurses were able to arrange for interpreter services for non-English speaking parents/ carers and language-appropriate written materials were provided for the major ethnic groups (such as Vietnamese, 
Chinese, Indian sub-continent and Arabic) living in this region.

\section{Data collection}

Basic demographic, biomedical and infant feeding information were collected via a baseline telephone interview conducted when the child was 8 weeks old. Follow-up interviews were conducted at 17, 34 and 52 weeks postpartum. The questionnaire used in this study was adapted from the first and second Perth Infant Feeding studies $[16,17,26]$. At each interview, information was collected on infant feeding practices including breastfeeding, the use of infant formula, and the introduction of complementary foods including solids and other fluids. If mothers had introduced solids to their infants, they were asked a closed-ended question on the primary reason for early introduction of solids to their infants.

\section{Outcome measure}

The outcome measure for this study was the age (in weeks) at which solids were introduced for the first time in infants. Very early introduction of solids was considered to be before 17 weeks of age, considering the recommendations from the 2016 Australian Infant Feeding Summit [14] and the ESPGHAN [11, 12].

\section{Exposure measures}

A variety of sociodemographic and biomedical characteristics identified in other studies and considered to be associated with the age of introduction of solids were investigated. The sociodemographic variables included maternal age, mother's education level, marital status, mother's and her partner's country of birth, mother's occupation at 12 months postpartum, mother's employment status at 12 months postpartum, and socioeconomic status. Mothers' provided their residential postcode and this information was used to classify their socioeconomic status (SES) as per the Census Index of Relative Socioeconomic Disadvantage. The biomedical factors include gestational age, parity, infant's gender, infant birth weight, delivery method, initiation and duration of breastfeeding, feeding method at 4 weeks postpartum, and maternal smoking and alcohol intake during or after pregnancy.

\section{Statistical analysis}

The Statistical Package for Social Sciences, Version 24 (SPSS for Windows, SPSS Inc., Chicago, IL, USA) was used to analyse the data. The primary reason for introducing solids to the infants before 17 weeks were analysed using frequency distribution.

Univariate logistic regression was initially employed to explore the relation between introduction of solids before 17 weeks and each individual explanatory variable.
Later, a multivariate logistic regression analysis was performed to determine which variables were independently predictive of the introduction of solids before 17 weeks of age. All explanatory variables were entered into the full model which was reduced using the backward stepwise procedure ( $\mathrm{p}$ for removal $<0.05$ ) and the fitness of model was assessed at every step to avoid dropping nonsignificant variables that affected the model fitness. All variables in the final model were variables for which, when excluded, the change in deviance compared with the corresponding $X^{2}$ test statistic on the relevant degrees of freedom was significant.

Survival analysis was used to examine the association between timing of introduction of solids with the duration of breastfeeding. The effect of timing of introduction of solids on the duration of breastfeeding was evaluated using the Kaplan-Meier estimate of "survival" (continuation of breastfeeding) and the log-rank test was used to assess the quality of the survival curves.

\section{Ethical considerations}

Ethics approvals for this study were obtained from the former Sydney South West Area Health Service - RPAH Zone (ID number X08-0115), Liverpool Hospital, University of Sydney, and Western Sydney University. All participants signed a written consent form to be a part of this study.

\section{Results}

Of the 1035 mother-infant dyads that were recruited into the HSHK study, 934 completed the interviews at 8 , 17,34 , and 52 weeks. The median age for the introduction of solids was 22 weeks (Interquartile range 18, 24) with the peak timing of introduction of solids at 24 weeks (Fig. 1). In total, 13.6\% $(n=127)$ of infants had received solids before 17 weeks and $76.9 \% \quad(n=719)$ received their first solids before 26 weeks of age.

There was a significant association between the timing of introduction of solids and the duration of breastfeeding ( $\log$ rank test $X^{2}=31.71, \mathrm{df}=1, p<0.001$ ) (Fig. 2). The median breastfeeding duration for mothers who introduced solids at or after 17 weeks breastfed was 27.6 weeks compared with 17.5 weeks for those mothers who introduced solids before 17 weeks.

A variety of sociodemographic factors were associated with very early introduction of solids (Table 1). Single women were more likely than married women to introduce solids to their babies very early. Whereas older women, University-educated women, and women in professional occupations were less likely to introduce solids before 17 weeks compared to women who were younger, dropped out of school, or listed their occupations as home duties or student, respectively. Women who migrated to Australian from Vietnam, China, the 


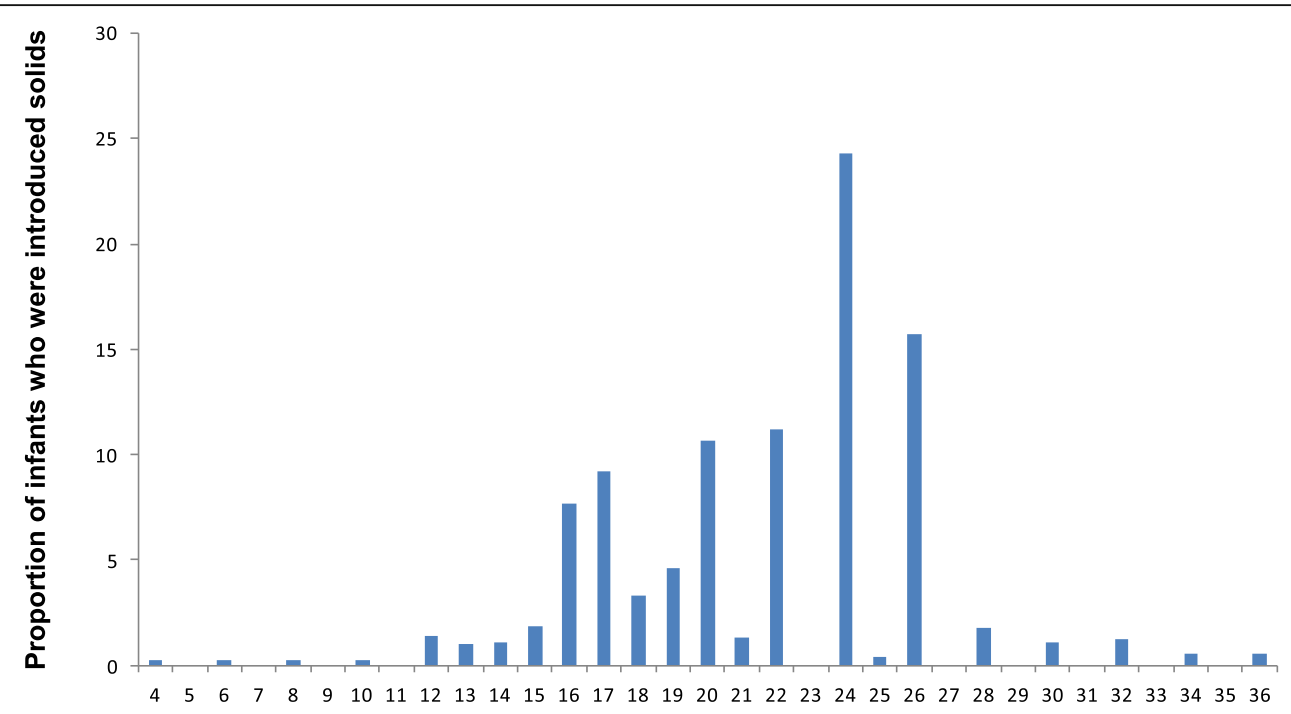

Age (in weeks) when solids were introduced

Fig. 1 The distribution of age at which solid foods were first introduced

Indian sub-continent and other Asian countries were less likely to introduce solids before 17 weeks compared to those born in Australia.

The list of biomedical factors associated with very early introduction of solids are shown in Table 2 . Mothers who had initiated breastfeeding were less likely to introduce solids before 17 weeks compared with those who did not initiate breastfeeding. Whereas those women who were formula-feeding at 4 weeks postpartum and those who smoked cigarettes during pregnancy or were current smokers were more likely to introduce solids to their babies very early.

Table 3 shows the factors that independently predict the very early introduction of solids. After adjusting for covariates, single mothers had more than twice the odds of introducing solids before the age of 17 weeks compared to married women $\left(\mathrm{OR}=2.35, \mathrm{CI}_{95}\right.$ 1.33-4.16). The odds of introducing solids very early decreased with increasing maternal age and compared to women less than 25 years of age, those who were 35 years or older

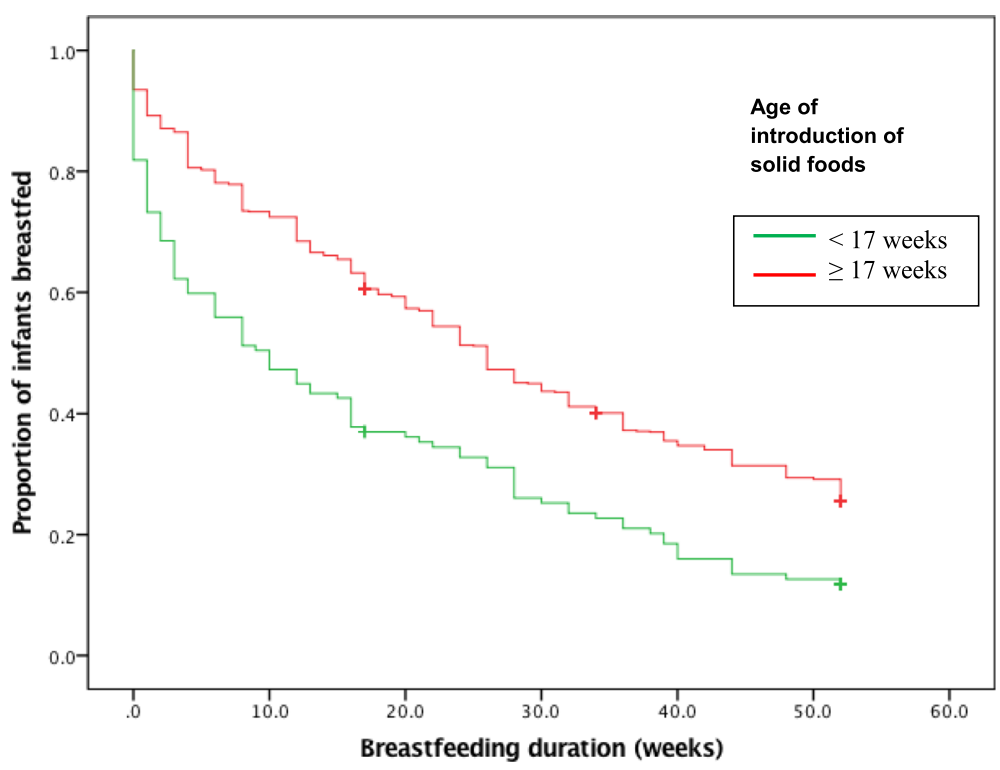

Fig. 2 The association of breastfeeding duration and age of introduction of solid foods 
Table 1 Association between sociodemographic factors and very early introduction of solid foods $(<17$ weeks) $(n=934)$

\begin{tabular}{|c|c|c|c|c|}
\hline \multirow[t]{3}{*}{ Variable } & \multirow{3}{*}{$\begin{array}{l}\text { Solids introduced } \\
<17 \text { weeks } \\
\text { N (\%) }\end{array}$} & \multirow{3}{*}{$\begin{array}{l}\text { Solids introduced }^{a} \\
\geq 17 \text { weeks } \\
N(\%)\end{array}$} & \multicolumn{2}{|c|}{ Univariate odds ratio $^{\mathrm{b}}$} \\
\hline & & & & \\
\hline & & & OR & $\mathrm{Cl}_{95}$ \\
\hline \multicolumn{5}{|l|}{ Maternal age (years) } \\
\hline$<25$ & $30(32.6)$ & $62(67.4)$ & 1.00 & \\
\hline $25-29$ & $36(14.1)$ & $219(85.9)$ & $0.34^{* * *}$ & $0.19,0.60$ \\
\hline $30-34$ & $44(12.5)$ & $307(87.5)$ & $0.30^{* * *}$ & $0.17,0.51$ \\
\hline$\geq 35$ & $17(7.2)$ & $219(92.8)$ & $0.16^{* * *}$ & $0.08,0.31$ \\
\hline \multicolumn{5}{|l|}{ Maternal education } \\
\hline$<$ Year 12 & $33(23.4)$ & $108(76.6)$ & 1.00 & \\
\hline Year 12 completed & $36(17.3)$ & $172(82.7)$ & 0.69 & $0.40,1.16$ \\
\hline College/TAFE & $23(12.9)$ & $155(87.1)$ & $0.49^{*}$ & $0.27,0.87$ \\
\hline University & $35(8.6)$ & $372(91.4)$ & $0.31^{* * *}$ & $0.18,0.52$ \\
\hline \multicolumn{5}{|l|}{ Marital Status } \\
\hline Married & 79 (10.8) & $655(89.2)$ & 1.00 & \\
\hline Living with a partner/ De facto & $18(16.4)$ & $92(83.6)$ & 1.62 & $0.93,2.83$ \\
\hline Single Mother & $30(33.3)$ & $60(66.7)$ & $4.15^{* * *}$ & $2.52,6.81$ \\
\hline \multicolumn{5}{|l|}{ Mother's country of birth } \\
\hline Australia & $77(17.7)$ & $359(82.3)$ & 1.00 & \\
\hline China & $3(5.4)$ & $53(94.6)$ & $0.26^{*}$ & $0.80,0.87$ \\
\hline Vietnam & $12(9.1)$ & $120(90.9)$ & $0.47^{*}$ & $0.25,0.89$ \\
\hline Asia Other & $6(5.5)$ & $104(94.5)$ & $0.27^{* *}$ & $0.11,0.64$ \\
\hline Middle-East/ Africa & $9(11.1)$ & $72(88.9)$ & 0.58 & $0.28,1.22$ \\
\hline Others & $20(16.9)$ & $98(83.1)$ & 0.95 & $0.55,1.63$ \\
\hline \multicolumn{5}{|l|}{ Partner's country of birth } \\
\hline Australia & $59(16.4)$ & $300(83.6)$ & 1.00 & \\
\hline China & $2(4.8)$ & $40(95.2)$ & 0.25 & $0.06,1.08$ \\
\hline Vietnam & $8(7.0)$ & $107(93.0)$ & $0.38^{*}$ & $0.18,0.82$ \\
\hline Asia Other & $7(6.7)$ & $98(93.3)$ & $0.36^{*}$ & $0.16,0.82$ \\
\hline Middle-East/ Africa & $12(12.5)$ & $84(87.5)$ & 0.73 & $0.37,1.41$ \\
\hline Others & $12(10.0)$ & $108(90.0)$ & 0.57 & $0.29,1.09$ \\
\hline \multicolumn{5}{|l|}{ Mother's occupation } \\
\hline Home duties/ student & $32(18.8)$ & $138(81.2)$ & 1.00 & \\
\hline Unskilled & $22(13.0)$ & $147(87.0)$ & 0.65 & $0.36,1.17$ \\
\hline Sales/Clerical & $43(14.7)$ & $250(85.3)$ & 0.74 & $0.45,1.23$ \\
\hline Managers & $9(14.8)$ & $52(85.2)$ & 0.75 & $0.33,1.67$ \\
\hline Professionals & $21(8.7)$ & $220(91.3)$ & $0.41^{* *}$ & $0.23,0.74$ \\
\hline \multicolumn{5}{|l|}{ Mother's employment status } \\
\hline Not working at 12 months & $71(14.5)$ & $420(85.5)$ & 1.00 & \\
\hline Return to work $<6$ months & $33(17.6)$ & $155(82.4)$ & 1.26 & $0.80,1.98$ \\
\hline Return to work 6-12 months & $18(8.1)$ & $203(91.9)$ & 0.53 & $0.31,0.90$ \\
\hline \multicolumn{5}{|c|}{ Index for Relative Socioeconomic Disadvantage } \\
\hline Least Disadvantaged & $6(12.0)$ & $44(88.0)$ & 1.00 & \\
\hline 2nd Quintile & $36(15.1)$ & $202(84.9)$ & 1.31 & $0.52,3.29$ \\
\hline 3rd Quintile & $7(8.8)$ & $73(91.3)$ & 0.70 & $0.22,2.23$ \\
\hline
\end{tabular}


Table 1 Association between sociodemographic factors and very early introduction of solid foods ( $<17$ weeks) ( $n=934)$ (Continued)

\begin{tabular}{|c|c|c|c|c|}
\hline \multirow[t]{3}{*}{ Variable } & \multirow{3}{*}{$\begin{array}{l}\text { Solids introduced } \\
<17 \text { weeks } \\
\mathrm{N}(\%)\end{array}$} & \multirow{3}{*}{$\begin{array}{l}\text { Solids introduced } \\
\geq 17 \text { weeks } \\
N(\%)\end{array}$} & \multicolumn{2}{|c|}{ Univariate odds ratio $^{b}$} \\
\hline & & & & \\
\hline & & & OR & $\mathrm{Cl}_{95}$ \\
\hline 4th Quintile & $19(10.4)$ & $164(89.6)$ & 0.85 & $0.32,2.25$ \\
\hline Most Disadvantaged & $59(15.4)$ & 324 (84.6) & 1.34 & $0.55,3.28$ \\
\hline
\end{tabular}

${ }^{a}$ The total of the categories do not always add up to 934 due to missing or incomplete data for some items

${ }^{b}$ The univariate odds ratio indicates the likelihood of early introduction of solid foods

OR odds ratio, $\mathrm{Cl}_{95}-95 \%$ confidence interval

${ }^{*} p<0.05{ }^{* *} p<0.01 * * * 0<0.001$

were $72 \%$ less likely to introduce solids very early $(\mathrm{OR}=$ 0.28, $\mathrm{CI}_{95}$ 0.14-0.58). Women who had returned to work between 6 to 12 months postpartum were $46 \%$ less likely to introduce solids very early compared with those who were not working at 12 months postpartum $(\mathrm{OR}=0.54$, $\mathrm{CI}_{95}$ 0.30-0.97). Compared to women born in Australia, migrant women from Vietnam $\left(\mathrm{OR}=0.42, \mathrm{CI}_{95}\right.$ 0.21$0.84)$ and other Asian countries other than China $(\mathrm{OR}=$ $0.30, \mathrm{Cl}_{95}$ 0.12-0.79) were less likely to introduce solids to their infants before 17 weeks.

Only one biomedical factor was independently associated with the risk of introducing solids very early: mothers who were exclusively formula-feeding their infants at 4

$\mathrm{s}$ postpartum were more than twice as likely to introduce solids very early $\left(\mathrm{OR}=2.34, \mathrm{CI}_{95} 1.49-3.66\right)$ compared to those who were fully breastfeeding at 4 weeks postpartum.

Table 4 shows the mothers' self-reported reasons for very early introduction of solids $(n=127)$. The main reasons given were: their baby was hungry $(n=45,35.4 \%)$, their baby was old enough to start solids ( $n=33,26.0 \%)$, they were advised by family and/or peers $(n=21,16.5 \%)$, they used solids to settle the baby or help them to sleep through the night $(n=15,11.8 \%)$ and/or they believed their baby was showing an interest in solids $(n=13$, $10.3 \%$ ), for example by putting their hands or other objects in their mouth and chewing on them or showing an interest in the parent's food.

\section{Discussion}

Since 2003, Australian mothers have been recommended to introduce solids to their infants at around 6 months of age $[9,27]$. This ongoing cohort study commenced in late 2009, when this recommendation had been in place for approximately 6 years. However, a recent consensus from the Australian Infant Feeding Summit emphasised that "When your infant is ready, at around six months, but not before four months, start to introduce a variety of solids, starting with iron rich foods, while continuing breastfeeding" [14]. Similarly, ESPGHAN [11, 12] and European Food Safety Authority [13] recommend that complementary foods should be introduced "no earlier than 17 weeks and no later than 26 weeks". While nearly $80 \%$ of infants in this study were introduced solids before 26 weeks, only $13.6 \%$ had received solids very early (before 17 weeks or 4 months). This percentage is much lower than that observed in the Perth Infant Feeding Study II (PIFS-II) [16] conducted in 2002/2003 when the recommended timing of introduction of solids was 'between 4 and 6 months'. In PIFS-II, 44\% of infants had received solids before 17 weeks and 93\% before 6 months. Median age of introduction of solids in the current study was 22 weeks which was almost 4.5 weeks later than in the PIFS-II [16].

The 2010 Australian National Infant Feeding Survey [28] reported that $28.4 \%$ infants residing in NSW and $35.3 \%$ infants nationally within Australia received soft/ semi-solid/solid foods by the age of 4 months. Hence, the current study showed better concordance with the infant feeding recommendations. Overall, the results of the present study and other contemporaneous Australian studies $[28,29]$ suggest a gradual shift towards introduction of solids closer to the recommended timing at the population level [9].

In this current study, a significant negative association was reported between very early introduction of solids and the duration of breastfeeding. Those mothers who introduced solids at or after 17 weeks breastfed their children an average of 10 weeks longer than those who introduced solids before 17 weeks. This finding is consistent with studies from France [30], England [31], Denmark [32] and other studies in Australia [16]; all of which found that early introduction of solids was associated with a shorter duration of breastfeeding.

There was an independent association between very early introduction of solids and certain sociodemographic and biomedical factors. Younger mothers were more likely to introduce solids very early, which is also a common finding in previous studies [29-31]. Several studies have recognised single mothers as a potential predictor for shorter duration of breastfeeding and early introduction to solids [15, 33, 34]. This association was also seen in the current study. It has been suggested that this association is due to increased stress from a lack of paternal support [33]. 
Table 2 Association between biomedical factors and very early introduction of solid foods ( $<17$ weeks) $(n=934)$

\begin{tabular}{|c|c|c|c|c|}
\hline \multirow[t]{3}{*}{ Variables } & \multirow{3}{*}{$\begin{array}{l}\text { Solids } \\
\text { introduced }^{a} \\
<17 \text { weeks } \\
N(\%)\end{array}$} & \multirow{2}{*}{$\begin{array}{l}\text { Solids } \\
\text { introduced }^{\mathrm{a}} \\
\geq 17 \text { weeks } \\
\mathrm{N}(\%)\end{array}$} & \multicolumn{2}{|c|}{$\begin{array}{l}\text { Univariate odds } \\
\text { ratio }^{\text {b }}\end{array}$} \\
\hline & & & & \\
\hline & & & OR & $\mathrm{Cl}_{95}$ \\
\hline \multicolumn{5}{|l|}{ Parity } \\
\hline Primiparous & $61(13.1)$ & $406(86.9)$ & 1.00 & \\
\hline Multiparous & $66(14.1)$ & 401 (85.9) & 1.09 & $0.75,1.59$ \\
\hline \multicolumn{5}{|l|}{ Infant gender } \\
\hline Female & 59 (12.9) & $398(87.1)$ & 1.00 & \\
\hline Male & $68(14.3)$ & $409(85.7)$ & 1.12 & $0.77,1.63$ \\
\hline
\end{tabular}

Infant birth weight

$\begin{array}{lllll}\geq 2500 \mathrm{~g} & 121(13.6) & 767(86.4) & 1.00 & \\ <2500 \mathrm{~g} & 6(13.0 & 40(87.0) & 0.95 & 0.39,2.29\end{array}$

Gestational age

$\begin{array}{lllll}\geq 37 \text { weeks } & 120(13.9) & 746(86.1) & 1.00 & \\ <37 \text { weeks } & 7(10.3) & 61(89.7) & 0.71 & 0.32,1.60\end{array}$

Method of delivery

$\begin{array}{lllll}\text { Vaginal } & 94(14.4) & 558(85.6) & 1.00 & \\ \text { Caesarean } & 33(11.7) & 249(88.3) & 0.79 & 0.52,1.20\end{array}$

Breastfeeding initiation

$\begin{array}{lllll}\text { No } & 23(30.7) & 52(69.3) & 1.00 & \\ \text { Yes } & 104(12.1) & 755(87.9) & 0.31^{* * *} & 0.18,0.53\end{array}$

Feeding method at 4 weeks

$\begin{array}{lllll}\text { Fully breastfed } & 62(10.6) & 524(89.4) & 1.00 & \\ \text { Partially breastfed } & 13(9.0) & 131(91.0) & 0.84 & 0.45,1.57 \\ \text { Fully formula fed } & 52(25.5) & 152(74.5) & 2.89^{* * *} & 1.92,4.36\end{array}$

Smoking status of the mother postpartum

$\begin{array}{lllll}\text { No } & 100(11.8) & 751(88.2) & 1.00 & \\ \text { Yes } & 27(32.5) & 56(67.5) & 3.62^{* * *} & 2.19,6.00\end{array}$

Smoking status of the mother during pregnancy

$\begin{array}{lllll}\text { No } & 108(12.2) & 775(87.8) & 1.00 & \\ \text { Yes } & 19(37.3) & 32(62.7) & 4.26^{* * *} & 2.33,7.78\end{array}$

Alcohol drinking status of the mother postpartum

$\begin{array}{lllll}\text { No } & 78(12.3) & 554(87.7) & 1.00 & \\ \text { Yes } & 49(16.2) & 253(83.8) & 1.38 & 0.93,2.03\end{array}$

Alcohol drinking status of the mother during pregnancy

\begin{tabular}{lllll} 
No & $111(13.2)$ & $731(86.8)$ & 1.00 & \\
Yes & $16(17.4)$ & $76(82.6)$ & 1.39 & $0.78,2.46$ \\
\hline
\end{tabular}

${ }^{a}$ The total of the categories do not always add up to 934 due to missing or incomplete data for some items

${ }^{b}$ The univariate odds ratio indicates the likelihood of early introduction of solid foods

OR odds ratio; $\mathrm{Cl}_{95}-95 \%$ confidence interval

*** $p<0.001$

In the current study, employment status of the mother was defined as 'time lapse for returning to work following child birth' i.e., if and when a mother had returned
Table 3 Sociodemographic and biomedical factors independently ${ }^{a}$ associated with very early introduction of solid foods (< 17 weeks) $(n=934)$

\begin{tabular}{ccccc}
\hline Variable $^{\mathrm{b}}$ & $\begin{array}{l}\text { Mean age of } \\
\text { introduction } \\
\text { of solids (weeks) }\end{array}$ & AdjOR $^{c}$ & $\mathrm{Cl}_{95}$ & $p$-value \\
\hline $\begin{array}{l}\text { Sociodemographic factors } \\
\text { Maternal age (years) }\end{array}$ & & & & \\
$<25$ & 19.65 & 1.00 & & \\
$25-29$ & 21.52 & 0.53 & $0.28,0.99$ & 0.048 \\
$30-34$ & 21.87 & 0.47 & $0.26,0.87$ & 0.015 \\
$\geq 35$ & 22.26 & 0.28 & $0.14,0.58$ & 0.001
\end{tabular}

Mother's country of birth

$\begin{array}{lllll}\text { Australia } & 20.97 & 1.00 & & \\ \text { China } & 22.58 & 0.39 & 0.12,1.32 & 0.131 \\ \text { Vietnam } & 23.44 & 0.42 & 0.21,0.84 & 0.013 \\ \text { Asia Other } & 23.22 & 0.30 & 0.12,0.79 & 0.014 \\ \text { Middle-East/ Africa } & 21.51 & 0.64 & 0.29,1.39 & 0.261 \\ \text { Others } & 20.51 & 1.07 & 0.60,1.93 & 0.815\end{array}$

Maternal employment status

\begin{tabular}{|c|c|c|c|c|}
\hline $\begin{array}{l}\text { Not working at } \\
12 \text { months } \\
\text { post-partum }\end{array}$ & 21.77 & 1.00 & & \\
\hline $\begin{array}{l}\text { Returned to } \\
\text { work }<6 \text { months } \\
\text { post-partum }\end{array}$ & 21.20 & 1.42 & $0.87,1.92$ & 0.160 \\
\hline $\begin{array}{l}\text { Returned to work } \\
6-12 \text { months } \\
\text { post-partum }\end{array}$ & 21.83 & 0.54 & $0.30,0.97$ & 0.039 \\
\hline \multicolumn{5}{|l|}{ Marital Status } \\
\hline Married & 21.98 & 1.00 & & \\
\hline $\begin{array}{l}\text { Living with a } \\
\text { partner/ De facto }\end{array}$ & 21.59 & 1.19 & $0.65,2.18$ & 0.577 \\
\hline Single Mother & 19.12 & 2.35 & $1.33,4.16$ & 0.003 \\
\hline \multicolumn{5}{|l|}{ Siomedical factors } \\
\hline \multicolumn{5}{|l|}{$\begin{array}{l}\text { Feeding method at } \\
4 \text { weeks }\end{array}$} \\
\hline Fully breastfed & 21.97 & 1.00 & & \\
\hline Partially breastfed & 21.94 & 0.98 & $0.51,1.92$ & 0.970 \\
\hline Fully formula fed & 20.58 & 2.34 & $1.49,3.66$ & 0.000 \\
\hline
\end{tabular}

${ }^{a}$ Non-significant variables were partner's country of birth, mother's occupation, index of relative socioeconomic disadvantage, parity, infant gender, infant birth weight, mother took antibiotics during pregnancy and labour, smoking status of the mother during pregnancy, alcohol status of the mother in pregnancy and postpartum, method of delivery

${ }^{b}$ All variables in the final model were variables for which, when excluded, the change in deviance compared with the corresponding $\mathrm{X}^{2}$ test statistic on the relevant degrees of freedom was significant

${ }^{c}$ AdjOR Adjusted odds ratio, $\mathrm{Cl}_{95}-95 \%$ confidence interval

to work during the first 12 months postpartum. The association between employment status and age of introduction was not in the direction expected and mothers who resumed work within 6-12 months after giving birth were less likely to introduce solids very early 
Table 4 Reasons for introducing solid foods before 17 weeks of age $(n=127)$

\begin{tabular}{lll}
\hline Reason & N & $\%$ \\
\hline Baby hungry & 45 & 35.4 \\
Baby old enough to wean & 33 & 26.0 \\
Advised by family and/or friends & 21 & 16.5 \\
To settle the baby/help him/her sleep at night $^{\text {Baby interested }}{ }^{\text {a }}$ & 15 & 11.8 \\
\hline
\end{tabular}

${ }^{a}$ Interest indicated by baby putting hands and other objects into mouth and/ or chewing hands and other objects or interest towards the parent's food

compared to mothers who had not returned to work at 12 months postpartum. While, returning to work within 6 months post-partum compared to not returning to work at 12 months was not associated with very early introduction of solids. Other studies have found no association between early introduction of solids and employment status [16, 30].

Maternal ethnicity (country of birth) was found to be a strong predictor for very early introduction of solids with mothers born in Vietnam and other Asian countries including the Indian sub-continent, were less likely to introduce solids very early to their infants compared with mothers born in Australia. This suggests that very early introduction of solids might be influenced by some cultural and ethnic factors. Ethnic and cultural associations of early introduction of solids have been reported in the literature $[16,35,36]$. An earlier study on infant feeding practices in Sydney found that Vietnamese-born women had optimal infant feeding practices as a result of remaining in a close community network maintaining traditional customs [37]. Similarly, having support from family and health professionals from a similar cultural background may support optimal infant feeding practices [38]. In contrast, a recent systematic review examined complementary feeding practices of South Asian women living in the United Kingdom (UK) and in South Asian countries (Manikam et al., 2016). Among women who had migrated to the UK, there was lower accordance with recommended infant feeding practices than among women who remained in their country of birth and these practices were influenced by low acculturation levels and conflicting information received from health professional, family elders, and community leaders. In this study, reasons for not introducing solids earlier by Vietnamese and Indian mothers were not explored and it is therefore difficult to draw conclusions.

Mothers who fully formula-fed their infant at 4 weeks postpartum were twice as likely to introduce solids earlier than 17 weeks compared to mothers who were fully breastfeeding their infants at 4 weeks postpartum. This finding aligns with a previous Australian study [39]. In a study in China, Tang et al. [18] reported that infants given formula regularly within the first 6-months of life were at a higher risk of receiving complementary foods early. Exclusive formula feeding is believed to be linked with impairment of appetite self-regulatory mechanisms which leads to infants demanding solids earlier without subsequent reduction in milk consumption during the complementary feeding phase [40]. Such impairment in early stage of life might pose long-term health complication such as increased risk of overweight and obesity in adulthood [41].

Among mothers that introduced solids to their babies before 17 weeks, the foremost self-reported reason was that they perceived that their child was "hungry" and breast milk and/or formula alone could not satisfy their child's appetite. Brown and Rowan [42], reported 'infant hunger' as the principal reason for early introduction of solids, with other reasons being 'infant weight and behaviour'. Similar findings have been reported in other studies [4, 43]. 'Pressure and/or advice from others' was also a commonly reported reason for early introduction of solids in these studies [4, 42, 43], and this was also observed in current study. In the current study, mothers also perceived that their babies were 'ready for solids'. Similar finding has been reported elsewhere and it is considered that multiple sources of information such as health practitioners, family, friends, and media can be conflicting and insensitive to the needs of mothers [44]. Effective interventions are therefore needed to educate mothers on the scientifically recommended age window for introducing solids rather than relying on their personal judgement on infant developmental readiness.

\section{Study strengths and limitations}

Mothers from socioeconomically disadvantaged and ethnically diverse groups, which are often underrepresented in research of this kind, were the focus of this study. The data were collected prospectively soon after birth and at three additional time points over a total 12 month period postpartum, thereby minimising the potential of 'recall bias' and 'heaping of data' [45] in relation to events of interest. The time of introducing solids was measured in weeks rather than months which allows for precise measurement of the time of event (i.e., the age of introducing solids) and clearly described early introduction of solids as "before 17 weeks". Many studies $[34,46]$ report infant feeding patterns in months and define early introduction of solids as "before 4 months" and it therefore remains unclear if this refers to completed months of age. Researchers also do not provide a standardised criterion for converting months to weeks or vice versa and these conversions are often inconsistently determined and reported. Such differences make it difficult to compare findings across studies. It is highly 
recommended that "17 weeks of age" and "26 weeks of age" to be consistently adopted as the definition for four and 6 months of age, respectively.

There are several limitations of this study. First, the participants were recruited from public hospitals located in South Western Sydney therefore the observed associations in the current study may not reflect associations at the populations level within New South Wales or Australia at the time of this study. Second, the outcomes were measured based on self-reporting which might have led to social desirability bias. Further, for certain explanatory variables e.g., country of birth, the number of women in respective categories was small $(<5)$. Since a relatively small proportion of women introduced solid foods early, this resulted in a rare events bias which was reflected as large confidence intervals around the odds ratio [47]. Hence, a larger study sample of women would have provided more statistically robust findings and current study findings should be interpreted with care. Also, the peak timing of introduction of solids was at 24 weeks which might suggest that many women would have interpreted 24 weeks to be 6 months (based on the assumption that 4 weeks is equal to 1 month).

\section{Conclusion}

In a sample of 934 mother infant dyads in South West Sydney, the median age of introduction of solids was 22 weeks. Nearly $80 \%$ of mothers had introduced solids by the time their infant was 26 weeks ( 6 months) of age and $14 \%$ of mothers had introduced solids to their infants very early (before 17 weeks). Mothers who were young, single, and fully formula-feeding their infants at 4 weeks of age were more likely to introduce solids very early. Mothers born in Australia were also more likely to introduce solids very early. Mothers at risk of introducing solids very early should be provided broader social support to enable them to make informed decisions regarding the timing of introducing solids to their infants. Additionally, existing infant feeding guidelines and promotion initiatives should incorporate specific sections on educating mothers on how to interpret infant behaviour and what needs to be done if their child seems hungry and unsettled.

\footnotetext{
Acknowledgements

We would like to thank the staff from Sydney and South Western Sydney Local Health Districts for their continued support with the project. The authors are grateful to the Child and Family Health Nurses who recruited families to this birth cohort study. We would like to thank the families who are a part of the Healthy Smiles Healthy Kids study for their continued commitment to this ongoing cohort study.
}

\section{Authors' contributions}

AA, SB, JAS, JE, and DH and conceived the study. NM assisted in study coordination. AA performed the analysis and interpreted the results with assistance from AH and JAS. AA and NM prepared the first draft. All authors critically revised the manuscript and approved the final manuscript as submitted.

\section{Funding}

This project is supported by NHMRC Grants (1069861, 1033213, 1134075), NSW Health, Australian Dental Research Foundation, Western Sydney University, and Oral Health Foundation.

\section{Availability of data and materials}

The data of this study can't be shared publically due to the presence of sensitive (confidential) participants' information.

\section{Ethics approval and consent to participate}

Ethics approvals for this study were obtained from the former Sydney South West Area Health Service - RPAH Zone (ID number X08-0115), Liverpool Hospital, University of Sydney, and Western Sydney University. All participants signed a written consent form to be a part of this study.

\section{Consent for publication}

All research participants consented to use their data de-identified data for publishing in scientific publications.

\section{Competing interests}

The authors declare that they have no competing interests.

\section{Author details}

${ }^{1}$ School of Health Sciences, Western Sydney University Campbelltown Campus, Locked Bag 1797, Penrith, NSW 2751, Australia. ${ }^{2}$ Translational Health Research Institute, Western Sydney University, Locked Bag 1797, Penrith, NSW 2751, Australia. ${ }^{3}$ Discipline of Child and Adolescent Health, Sydney Medical School, Faculty of Medicine and Health, The University of Sydney, Westmead, NSW 2145, Australia. ${ }^{4}$ Oral Health Services, Sydney Local Health District and Sydney Dental Hospital, NSW Health, Surry Hills, NSW 2010, Australia. ${ }^{5}$ Cancer Australia, Surry Hills, NSW 2010, Australia. ${ }^{6}$ Sydney Dental School, Faculty of Medicine and Health, The University of Sydney, Surry Hills, NSW 2010, Australia. ${ }^{7}$ Oral Health Alliance, Oral Health Centre, University of Queensland, Brisbane, QLD 4006, Australia. ${ }^{8}$ Metro North Oral Health Services, Stafford, QLD, Australia. ${ }^{9}$ Australian Centre for Public and Population Health Research, Faculty of Health, University of Technology Sydney, Ultimo, NSW, Australia. ${ }^{10}$ Community Paediatrics, Sydney Local Health District, NSW Health, Croydon, Australia. ${ }^{11}$ School of Women's and Children's Health, University of New South Wales, Kensington, NSW, Australia. ${ }^{12}$ School of Medicine, Griffith University, Gold Coast, QLD, Australia. ${ }^{13}$ School of Public Health, Curtin University, Perth, WA, Australia.

Received: 30 August 2019 Accepted: 29 January 2020

Published online: 18 February 2020

\section{References}

1. Huh SY, Rifas-Shiman SL, Taveras EM, Oken E, Gillman MW. Timing of solid food introduction and risk of obesity in preschool-aged children. Pediatrics. 2011;127:e544-e51.

2. World Health Organization. Indicators for assessing infant and young child feeding practices: part 1: definitions: conclusions of a consensus meeting held 6-8 November 2007 in Washington DC, USA. 2008.

3. Duong DV, Binns CW, Lee AH. Introduction of complementary food to infants within the first six months postpartum in rural Vietnam. Acta Paediatr. 2005;94:1714-20.

4. Tarrant RC, Younger KM, Sheridan-Pereira M, White MJ, Kearney JM. Factors associated with weaning practices in term infants: a prospective observational study in Ireland. Br J Nutr. 2010;104:1544-54.

5. World Health Organization. Infant and child nutrition: global strategy for infant and young child feeding. Geneva: World Health Organization; 2002.

6. Kramer MS, Kakuma R. Optimal duration of exclusive breastfeeding. Cochrane Database Syst Rev. 2012;(Issue 8). Art. No.: CD003517. https://doi. org/10.1002/14651858.CD003517.pub2.

7. World Health Organization. Exclusive breastfeeding for six month best for babies everywhere. Geneva: Director of the Department of Communications, World Health Organization; 2011. 
8. Horta BL, Loret de Mola C, Victora CG. Long-term consequences of breastfeeding on cholesterol, obesity, systolic blood pressure and type 2 diabetes: a systematic review and meta-analysis. Acta Paediatr. 2015;104:30-7.

9. National Health and Medical Research Council. Infant Feeding Guidelines. Canberra: National Health and Medical Research Council; 2012.

10. American Academy of Pediatrics. Breastfeeding and the use of human Milk policy statement. Pediatrics. 2012;129:e827-e41.

11. Agostoni C, Decsi T, Fewtrell M, Goulet O, Kolacek S, Koletzko B, et al. Complementary feeding: a commentary by the ESPGHAN committee on nutrition. J Pediatr Gastroenterol Nutr. 2008;46:99-110.

12. Fewtrell M, Bronsky J, Campoy C, Domellöf M, Embleton N, Mis NF, et al. Complementary feeding: a position paper by the European Society for Paediatric Gastroenterology, Hepatology, and nutrition (ESPGHAN) committee on nutrition. J Pediatr Gastroenterol Nutr. 2017;64:119-32.

13. EFSA Panel on Dietetic Products, Nutrition and Allergies (NDA). Scientific Opinion on the appropriate age for introduction of complementary feeding of infants. EFSA J. 2009;7(12):1423[1-38 pp.]. https://doi.org/10.2903/j.efsa. 2009.1423. Available online: www.efsa.europa.eu.

14. Netting MJ, Campbell DE, Koplin JJ, Beck KM, McWilliam V, Dharmage SC, et al. An Australian consensus on infant feeding guidelines to prevent food allergy: outcomes from the Australian infant feeding summit. J Allergy Clin Immunol Pract. 2017;5:1617-24.

15. Wijndaele K, Lakshman R, Landsbaugh JR, Ong KK, Ogilvie D. Determinants of early weaning and use of unmodified cow's milk in infants: a systematic review. J Am Diet Assoc. 2009;109:2017-28.

16. Scott JA, Binns CW, Graham Kl, Oddy WH. Predictors of the early introduction of solid foods in infants: results of a cohort study. BMC Pediatr. 2009;9:60

17. Scott JA, Binns CW, Aroni RA. Breast-feeding in Perth: recent trends. Aust N Z J Public Health. 1996;20:210-1.

18. Tang L, Lee $A H$, Binns CW. Predictors of early introduction of complementary feeding: longitudinal study. Pediatr Int. 2015;57:126-30.

19. Manohar N, Hayen A, Bhole S, Arora A. Predictors of Early Introduction of Core and Discretionary Foods in Australian Infants-Results from HSHK Birth Cohort Study. Nutrients. 2020;12:258. https://doi.org/10.3390/nu12010258.

20. Australian Institute of Health and Welfare. Australia's Health 2012: Australia's health series no.13. Cat no. AUS 156. In: AlHW. Canberra: AlHW; 2012.

21. Centre for Epidemiology and Evidence. 2009-2010 Summary report from the New South Wales child health survey. Sydney: NSW Ministry of Health; 2012.

22. Arora A, Scott JA, Bhole S, Do L, Schwarz E, Blinkhorn AS. Early childhood feeding practices and dental caries in preschool children: a multi-centre birth cohort study. BMC Public Health. 2011;11:28.

23. Arora A, Manohar N, Hayen A, Bhole S, Eastwood J, Levy S, et al. Determinants of breastfeeding initiation among mothers in Sydney, Australia: findings from a birth cohort study. Int Breastfeed J. 2017;12:39.

24. Ogbo FA, Eastwood J, Page A, Arora A, McKenzie A, Jalaludin B, et al. Prevalence and determinants of cessation of exclusive breastfeeding in the early postnatal period in Sydney, Australia. Int Breastfeed J. 2016;12:16.

25. Arora A, Bedros D, Bhole S, Do LG, Scott J, Blinkhorn A, et al. Child and family health nurses' experiences of oral health of preschool children: a qualitative approach. J Public Health Dent. 2012;72:149-55.

26. Scott JA, Binns CW, Graham Kl, Oddy WH. Temporal changes in the determinants of breastfeeding initiation. Birth. 2006;33:37-45.

27. National Health Medical Research Council. Dietary guidelines for children and adolescents in Australia: incorporating the infant feeding guidelines for health workers| infant feeding guidelines for health workers. Canberra, Australia: NHMRC; 2003.

28. Australian Institute of Health and Welfare. 2010 Australian National Infant Feeding Survey: Indicator results. Canberra: Australian Institute of Health and Welfare; 2011

29. Magarey A, Kavian F, Scott JA, Markow K, Daniels L. Feeding mode of Australian infants in the first 12 months of life: an assessment against national breastfeeding indicators. J Hum Lact. 2016;32:NP95-NP104.

30. Boudet-Berquier J, Salanave B, de Launay C, Castetbon K. Introduction of complementary foods with respect to French guidelines: description and associated socio-economic factors in a nationwide birth cohort (Epifane survey). Matern Child Nutr. 2017;13:e12339. https://doi.org/10. $1111 / \mathrm{mcn} .12339$.
31. Hollis J, Crozier S, Inskip H, Cooper C, Godfrey K, Robinson S. Age at introduction of solid foods and feeding difficulties in childhood: findings from the Southampton Women's survey. Br J Nutr. 2016;116:743-50.

32. Kronborg H, Foverskov $E$, Væth M. Breastfeeding and introduction of complementary food in Danish infants. Scand J Soc Med. 2015;43:138-45.

33. Andrén Aronsson C, Uusitalo U, Vehik K, Yang J, Silvis K, Hummel S, et al. Age at first introduction to complementary foods is associated with sociodemographic factors in children with increased genetic risk of developing type 1 diabetes. Matern Child Nutr. 2015;11:803-14.

34. Tromp I, Briede S, Kiefte-De Jong J, Renders C, Jaddoe V, Franco O, et al. Factors associated with the timing of introduction of complementary feeding: the generation R study. Eur J Clin Nutr. 2013;67:625-30.

35. Sahota P, Gatenby LA, Greenwood DC, Bryant M, Robinson S, Wright J. Ethnic differences in dietary intake at age 12 and 18 months: the born in Bradford 1000 study. Public Health Nutr. 2016;19:114-22.

36. Castro PD, Kearney J, Layte R. A study of early complementary feeding determinants in the Republic of Ireland based on a cross-sectional analysis of the growing up in Ireland infant cohort. Public Health Nutr. 2015;18:292-302.

37. Reynolds B, Hitchcock NE, Coveney J. A longitudinal study of Vietnamese children born in Australia: infant feeding, growth in infancy and after five years. Nutr Res. 1988;8:593-603.

38. Rossiter JC, Yam B. Breastfeeding: how could it be enhanced? The perceptions of Vietnamese women in Sydney, Australia. J Midwifery Womens Health. 2000;45:271-6.

39. Brodribb W, Miller $Y$. Introducing solids and water to Australian infants. J Hum Lact. 2013;29:214-21.

40. Young BE, Krebs NF. Complementary feeding: critical considerations to optimize growth, nutrition, and feeding behavior. Curr Pediatr Rep. 2013;1:247-56.

41. Mehta UJ, Siega-Riz AM, Herring AH, Adair LS, Bentley ME. Pregravid body mass index is associated with early introduction of complementary foods. J Acad Nutr Diet. 2012;112:1374-9.

42. Brown A, Rowan H. Maternal and infant factors associated with reasons for introducing solid foods. Matern Child Nutri. 2016;12:500-15.

43. Moore AP, Milligan P, Goff LM. An online survey of knowledge of the weaning guidelines, advice from health visitors and other factors that influence weaning timing in UK mothers. Matern Child Nutr. 2014;10: $410-21$.

44. Clayton HB, Li R, Perrine CG, Scanlon KS. Prevalence and reasons for introducing infants early to solid foods: variations by Milk feeding type. Pediatrics. 2013;131:e1108-e14.

45. Jain A, Bongaarts J. Breastfeeding: patterns correlates and fertility effects. Stud Fam Plan. 1981:12:79-99.

46. Braid S, Harvey EM, Bernstein J, Matoba N. Early introduction of complementary foods in preterm infants. J Pediatr Gastroenterol Nutr. 2015;60:811-8.

47. Firth D. Bias reduction of maximum likelihood estimates. Biometrika. 1993; 80:27-38.

\section{Publisher's Note}

Springer Nature remains neutral with regard to jurisdictional claims in published maps and institutional affiliations.

Ready to submit your research? Choose BMC and benefit from:

- fast, convenient online submission

- thorough peer review by experienced researchers in your field

- rapid publication on acceptance

- support for research data, including large and complex data types

- gold Open Access which fosters wider collaboration and increased citations

- maximum visibility for your research: over $100 \mathrm{M}$ website views per year

At $\mathrm{BMC}$, research is always in progress.

Learn more biomedcentral.com/submission 